J-Y. Park · K-G. Park • H-J. Kim • H-G. Kang •

J. D. Ahn · H-S. Kim • Y. M. Kim • S. M. Son •

I. J. Kim • Y. K. Kim • C. D. Kim • K-U. Lee · I-K. Lee

\title{
The effects of the overexpression of recombinant uncoupling protein 2 on proliferation, migration and plasminogen activator inhibitor 1 expression in human vascular smooth muscle cells
}

Received: 30 June 2004 / Accepted: 23 November 2004 / Published online: 13 April 2005

(C) Springer-Verlag 2005

\begin{abstract}
Aims/hypothesis: Increased oxidative stress in vascular smooth muscle cells (VSMCs) has been implicated in the pathogenesis of accelerated atherosclerosis in patients with diabetes mellitus. Uncoupling protein 2 (UCP-2) is an important regulator of intracellular reactive oxygen species (ROS) production. We hypothesised that UCP-2 functions as an inhibitor of the atherosclerotic process in VSMCs. Methods: Overexpression of human UCP-2 was performed in primary cultured human VSMCs (HVSMCs) via adenovirus-mediated gene transfer. Its effects on ROS production, AP-1 activity, plasminogen activator inhibitor $1(P A I-1)$ gene
\end{abstract}

J.-Y. Park · K.-U. Lee $(\bowtie)$

Department of Internal Medicine,

College of Medicine, University of Ulsan,

Poongnap- dong, Songpa-ku,

Seoul, 138-736, South Korea

e-mail: kulee@amc.seoul.kr

Tel.: +82-2-30103243

Fax: $+82-2-30106962$

K.-G. Park · H.-J. Kim · H.-G. Kang · J. D. Ahn •

H.-S. Kim · I.-K. Lee $(\bowtie)$

Department of Internal Medicine,

School of Medicine, Keimyung University,

194 Dongsan-dong, Joong-gu,

Daegu, 700-712, South Korea

e-mail: inkyulee@dsmc.or.kr

Tel.: +82-53-2507421

Fax: $+82-53-2507892$

Y. M. Kim

Asan Institute for Life Sciences,

Seoul, South Korea

S. M. Son · I. J. Kim · Y. K. Kim

Department of Internal Medicine,

College of Medicine,

Pusan National University,

Busan, South Korea

C. D. Kim

Department of Pharmacology,

College of Medicine,

Pusan National University,

Busan, South Korea expression, and cellular proliferation and migration were measured in response to high glucose and angiotensin II (Ang II) concentrations, two major factors in the pathogenesis of atherosclerosis in patients with diabetes and hypertension. Mitochondrial membrane potential and NAD $(\mathrm{P}) \mathrm{H}$ oxidase activity were also measured. Results: High glucose and Ang II caused transient mitochondrial membrane hyperpolarisation. They also significantly stimulated ROS production, $\mathrm{NAD}(\mathrm{P}) \mathrm{H}$ oxidase activity, mitochondrial membrane potential, AP-1 activity, PAI-1 mRNA expression, and proliferation and migration of HVSMCs. Adenovirus-mediated transfer of the UCP-2 gene reversed all of these effects. Conclusions/interpretation: The present study demonstrates that UCP-2 can modify atherosclerotic processes in HVSMCs in response to high glucose and Ang II. Our data suggest that agents increasing UCP-2 expression in vascular cells may help prevent the development and progression of atherosclerosis in patients with diabetes and hypertension.

Keywords Angiotensin II - Atherosclerosis ·

High glucose - Migration - Plasminogen activator inhibitor 1 - Proliferation - Reactive oxygen species . Uncoupling protein $2 \cdot$ Vascular smooth muscle cells

Abbreviations Ang II: angiotensin II - AP-1: activator protein 1 HVSMCs: human vascular smooth muscle cells - ODN: oligodeoxynucleotide - PAI-1: plasminogen activator inhibitor $1 \cdot$ ROS: reactive oxygen species . TMRM: tetramethylrhodamine $\cdot$ UCP: uncoupling protein - VSMCs: vascular smooth muscle cells

\section{Introduction}

The risk of cardiovascular disease is increased in patients with diabetes mellitus, especially when diabetes is combined with hypertension $[1,2]$. The proliferation and migration of vascular smooth muscle cells (VSMCs), leading to excessive accumulation of VSMCs within the arterial intima layer, are key processes in atherosclerosis [3, 4]. VSMCs within the intima produce various atherogenic mediators in- 
cluding plasminogen activator inhibitor 1 (PAI-1) [5]. This protein is the main physiological inhibitor of tissue-type plasminogen activator and is considered to be the most important inhibitor of fibrinolysis [6]. Moreover, in VSMCs, PAI-1 promotes neointimal formation after vascular injury $[7,8]$.

It is now well established that an increase in oxidative stress in vascular cells plays a key role in the pathogenesis of atherosclerosis $[9,10]$. High glucose and angiotensin II (Ang II) concentrations, which contribute to the pathogenesis of atherosclerosis in patients with diabetes and hypertension respectively, lead to intracellular oxidative stress [11, 12]. In previous studies, we demonstrated that oligodeoxynucleotide (ODN)-mediated inhibition of the redox-sensitive transcription factor activator protein 1 (AP-1) decreased high-glucose- and Ang-II-induced proliferation and PAI-1 gene expression in human VSMCs (HVSMCs) [13, 14]. These results support the concept that relatively high levels of oxidative stress in vascular cells induce atherogenic genes via redox-sensitive signalling pathways and transcription factors [10].

Although the relative contribution of the individual reactive oxygen species (ROS)-generating systems in the vasculature is still ambiguous, both cell membrane $\mathrm{NAD}(\mathrm{P}) \mathrm{H}$ oxidase and the mitochondrial electron-transport chain have been shown to play significant roles in the overproduction of ROS by Ang II $[12,15]$ and high glucose $[16,17]$. UCP-2 is a newly identified member of the mitochondrial anion carrier family and shares $60 \%$ sequence identity with the well-known thermogenic UCP-1 from brown adipose tissue [18]. Several lines of evidence suggest that UCP-2 is involved in the control of ROS production by mitochondria [19-21]. More recently, a direct role for UCP-2 in the regulation of atherogenesis has been suggested by the observation that bone marrow transplantation from UCP-2-deficient mice to LDL-receptor-deficient mice markedly increased atherosclerotic lesion size [22]. However, there has been no previous investigation of UCP-2 function in VSMCs. Therefore, the aim of this study was to investigate the possible role of UCP-2 in the regulation of atherogenesis in VSMCs.

\section{Materials and methods}

Cell culture HVSMCs were isolated from the thoracic aorta of organ transplantation donors by the explant method as described previously [14]. Tissue collection was approved by the ethics committee of the institution. Cells were cultured in DMEM (Gibco BRL, Gaithersburg, MD, USA) containing $20 \%$ fetal bovine serum (Hyclone, Logan, UT, USA). In each preparation, HVSMC purity was determined by positive staining with smooth-muscle-specific $\alpha$-actin monoclonal antibodies (Santa Cruz Biotechnology, Santa Cruz, CA, USA). All the cells were used within passages 5 and 6 . After reaching $90 \%$ confluency in $100-\mathrm{mm}$ dishes, cells were serum starved for $24 \mathrm{~h}$ and exposed to either control, normal glucose (DMEM containing 10\% serum and $5.5 \mathrm{mmol} / \mathrm{l} \mathrm{D}-$ glucose) or conditioned medium (DMEM containing 10\% serum and $22 \mathrm{mmol} / \mathrm{l} \mathrm{D}$-glucose).

Preparation of recombinant adenovirus The cDNA encoding the full-length human UCP-2 was inserted into the HindIII/BamHI site of the pAd-YC2 shuttle vector [23]. Shuttle vectors containing human UCP-2 cDNA and the rescue vector pJM17 [24, 25] were co-transfected into human embryonic kidney 293 (HEK-293) cells, which were cultured on 24-well plates the day before transfection. After 12 to 15 days, recombinants were identified by PCR [23], following which they were amplified in HEK-293 cells, and purified and isolated using $\mathrm{CsCl}$ (Sigma, St Louis, MO, USA). The preparations were collected and desalted and titres were determined by measuring plaque counts. Control adenovirus not containing UCP-2 (Ad-Null) was prepared and identified by the same method.

Measurement of intracellular $\mathrm{H}_{2} \mathrm{O}_{2}$ production HVSMCs were seeded into six-well plates containing cover glasses. After reaching $90 \%$ confluency, HVSMCs were incubated in serum-free media for $24 \mathrm{~h}$. Cells treated with $6 \times 10^{6}$ plaque-forming units of adenovirus containing the $U C P-2$ gene (Ad-UCP-2) or Ad-Null were cultured for $48 \mathrm{~h}$ in media containing $2 \%$ fetal bovine serum. After exposure to Ang II (100 nmol/l; Sigma) for $4 \mathrm{~h}, 10 \mu \mathrm{mol} / 1$ 2',7'-dichlorofluorescein diacetate (Sigma), a $\mathrm{H}_{2} \mathrm{O}_{2}$-sensitive fluorescent probe, were added and HVSMCs were cultured for 30 min. $\mathrm{H}_{2} \mathrm{O}_{2}$ production was quantified using Zeiss LSM 410 confocal scanning laser microscopy at an excitation wavelength of $488 \mathrm{~nm}$ and an emission wavelength of $515 \mathrm{~nm}$. Under the same imaging conditions, six images were analysed for each condition using the NIH program.

Measurement of $N A D(P) H$ oxidase activity HVSMCs were washed twice with PBS, then lysed with lysis buffer $(50 \mathrm{mmol} / \mathrm{l}$ Tris- $\mathrm{HCl}, 150 \mathrm{mmol} / \mathrm{l} \mathrm{NaCl}, 1 \mathrm{mmol} / \mathrm{l}$ EDTA, $1 \%$ Triton X-100, $10 \%$ glycerol, $1 \mathrm{mmol} / \mathrm{l} \mathrm{PMSF}, 1 \mathrm{mg} / \mathrm{ml}$ aprotinin, $1 \mathrm{mg} / \mathrm{ml}$ leupeptin) and incubated for $1 \mathrm{~h}$ on ice. The lysate was centrifuged at 12,000 $\mathrm{g}$ for $20 \mathrm{~min}$ and the supernatant was saved. Protein content was determined using the Bradford method (Bio-Rad, Hercules, CA, USA). $\mathrm{NAD}(\mathrm{P}) \mathrm{H}$ oxidase activity was measured by lucigenin chemiluminescence [26].

Measurement of mitochondrial membrane potential The degree of polarisation of the mitochondria was determined by loading with tetramethylrhodamine (TMRM; Molecular Probes, Eugene, OR, USA) as described previously [27]. Forty-eight hours after infecting cells with Ad-UCP-2 or Ad-Null, cells were seeded to 96-well culture plates and exposed to either control, Ang II (100 nmol/1) or high glucose $(22 \mathrm{mmol} / \mathrm{l} \mathrm{D}$-glucose) conditions for the given time periods. Cells were incubated with $50 \mathrm{nmol} / 1 \mathrm{TMRM}$ for $20 \mathrm{~min}$ at $37^{\circ} \mathrm{C}$ and then rinsed with Hanks' balanced salt solution $(10 \mathrm{mmol} / \mathrm{l}$ HEPES, $\mathrm{pH} 7.4,150 \mathrm{mmol} / \mathrm{l} \mathrm{NaCl}$, $5 \mathrm{mmol} / 1 \mathrm{KCl}, 1 \mathrm{mmol} / 1 \mathrm{MgCl}_{2}, 1.8 \mathrm{mmol} / 1 \mathrm{CaCl}_{2}$ ). The plate was immediately placed in a microplate spectrofluo- 
rometer (SPECTRAmax GEM-INI-XS; Molecular Devices, Sunnyvale, CA, USA), and the absorbance of TMRM was determined by 485-nm excitation and 590-nm emission.

Electrophoretic mobility shift assay Nuclear extracts were prepared from HVSMCs. DNA probes were labelled using $\left[\gamma-{ }^{32} \mathrm{P}\right] \mathrm{ATP}$ and T4 polynucleotide kinase. Following endlabelling, ${ }^{32}$ P-labelled ODNs were purified using a NAP-5 column. Protein-DNA binding reactions were performed as described previously [14]. Experimental conditions for competition studies were identical, except that appropriate competitor ODNs were added to the reaction mixtures in 50- to 100-fold molar excess before nuclear extracts were added.

RT-PCR Aliquots of total RNA $(1 \mu \mathrm{g})$ from each sample were reverse-transcribed into cDNA according to the instructions of the First Strand cDNA Synthesis Kit manufacturer (MBI, Vilnius, Lithuania). Equal amounts of the reverse transcriptional products were subjected to PCR amplification. The primers used for amplification of human UCP-2 were 5'-ATCTCCTGGGACGTAGCAG-3' (forward) and 5'-CCAGCTCAGCACAGTTTGAC-3' (reverse). The mRNA levels were normalised with $\beta$-actin mRNA levels.

Northern blot analysis The radiolabelled probes used for northern blot analysis were prepared by random primer labelling with $\left[\alpha-{ }^{32} \mathrm{P}\right] \mathrm{dCTP}$ using a random primer labelling kit (Amersham, Arlington Heights, IL, USA). Northern blot analysis was performed as described previously [14].

Cell growth assay HVSMCs were seeded on 96-well tissue culture plates. At 30\% confluency, they were rendered quiescent by incubation for $24 \mathrm{~h}$ in serum-free medium. After treatment with $6 \times 10^{6}$ plaque-forming units of Ad-UCP-2 or Ad-Null, Ang II (100 nmol/l) was added to the wells and cells were incubated at $37^{\circ} \mathrm{C}$ for a further $4 \mathrm{~h}$. The cell proliferation rate was determined using a WST cell counting kit (Wako, Osaka, Japan).

Cell migration assay HVSMCs were seeded on six-well plates at $90 \%$ confluency and were incubated in serumfree medium for $24 \mathrm{~h}$. They were then treated with $6 \times 10^{6}$ plaque-forming units of Ad-UCP-2 or Ad-Null and were wounded by razor scraping. After rinsing with PBS, Ang II (100 nmol/l) was added to the wells. Cells were allowed to migrate for $48 \mathrm{~h}$ and were then stained with haematoxylin and eosin. The extent of migration was calculated by direct cell counting.

Statistical analysis Results are expressed as means \pm SEM. Analysis of variance with a subsequent Duncan's test was used to determine statistical significance in multiple comparisons. A $p$ value of less than 0.05 was considered statistically significant. All experiments were performed at least three times.

\section{Results}

Expression of UCP-2 mRNA in HVSMCs and up-regulation by angiotensin II and high glucose We initially examined whether UCP-2 mRNA is basally expressed in HVSMCs and whether the level of expression changes in response to high glucose and Ang II. RT-PCR indicated that primary cultured HVSMCs do express UCP- 2 mRNA, and that its expression level was increased by both Ang II and high glucose (Fig. 1a, $p<0.01$ and $p<0.001$ respectively).

Adenovirus-mediated UCP-2 gene overexpression in HVSMCs To determine whether UCP-2 reduces the production of ROS, we used adenoviral infection to overexpress UCP-2 in HVSMCs. HVSMCs infected with adenoviruses containing UCP-2 (Ad-UCP-2) cDNA at doses of 3, 6 and $12 \times 10^{6}$ plaque-forming units/ml exhibited four-, $42-$ and

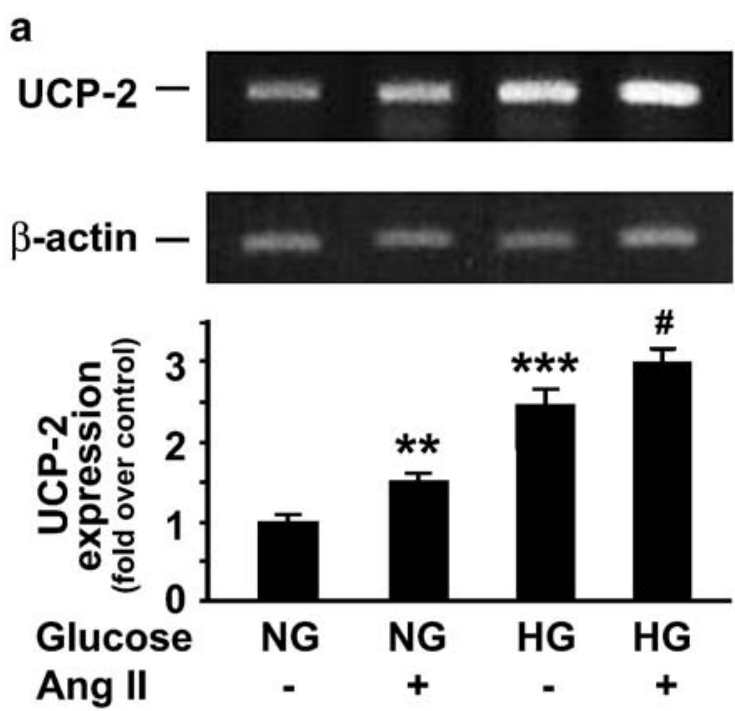

b
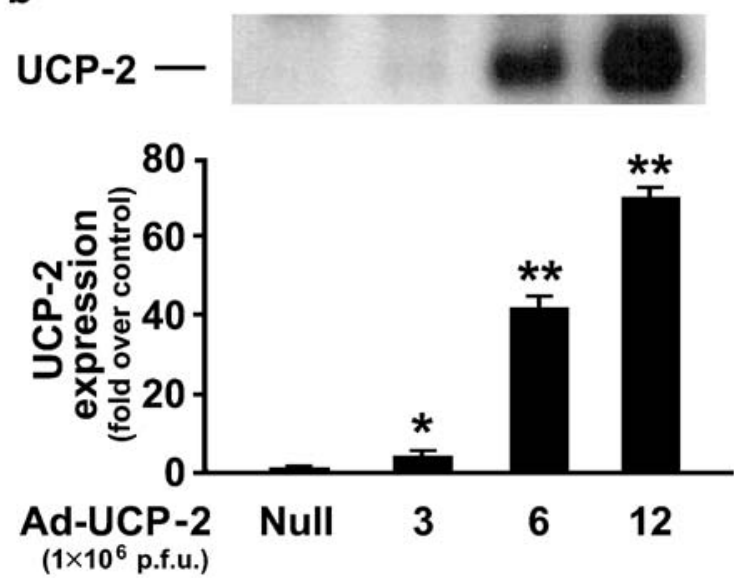

Fig. 1 Expression of UCP-2 mRNA (a) and adenovirus-mediated overexpression of UCP-2 (b) in HVSMCs. a $N G$, normal glucose $(5.5 \mathrm{mmol} / \mathrm{l}) ; H G$, high glucose $(22 \mathrm{mmol} / \mathrm{l}) ;$ Ang $I I$, angiotensin II $(100 \mathrm{nmol} / \mathrm{l}) .{ }^{* *} p<0.01$ vs NG; ${ }^{* * *} p<0.001$ vs NG; ${ }^{\#} p<0.05$ vs HG b Null, Ad-Null; p.f.u., plaque-forming units. ${ }^{*} p<0.05$ vs Null; ${ }^{* *} p<0.01$ vs Null 
69-fold increases in UCP-2 mRNA, respectively, compared with cells infected with Ad- $\beta$-gal (Fig. 1b). We used $6 \times 10^{6}$ plaque-forming units/ml of Ad-UCP-2 in subsequent experiments.

Suppression of $\mathrm{H}_{2} \mathrm{O}_{2}$ production by Ad-UCP-2 Ang II (100 nmol/l) and high glucose $(22 \mathrm{mmol} / \mathrm{l})$ increased the production of $\mathrm{H}_{2} \mathrm{O}_{2}$ compared with that observed under normal glucose $(5.5 \mathrm{mmol} / \mathrm{l})$ conditions ( $p<0.01$ for each). Transfection of Ad-UCP-2 significantly reduced $\mathrm{H}_{2} \mathrm{O}_{2}$ production induced by Ang II or high glucose, whereas transfection of Ad-Null did not influence this parameter (Fig. 2).

Effect of Ad-UCP-2 on NAD(P)H oxidase Both high glucose and Ang II increased the $\mathrm{NAD}(\mathrm{P}) \mathrm{H}$ oxidase activity compared with that observed under normal glucose conditions ( $p<0.05$ for each). Transfection of Ad-UCP-2 significantly reduced NAD(P)H oxidase activity (Fig. $3 \mathrm{a}$ ).

Effect of Ad-UCP-2 on the mitochondrial membrane potential The changes in the membrane potential in response to high glucose and Ang II were determined over a 24- or
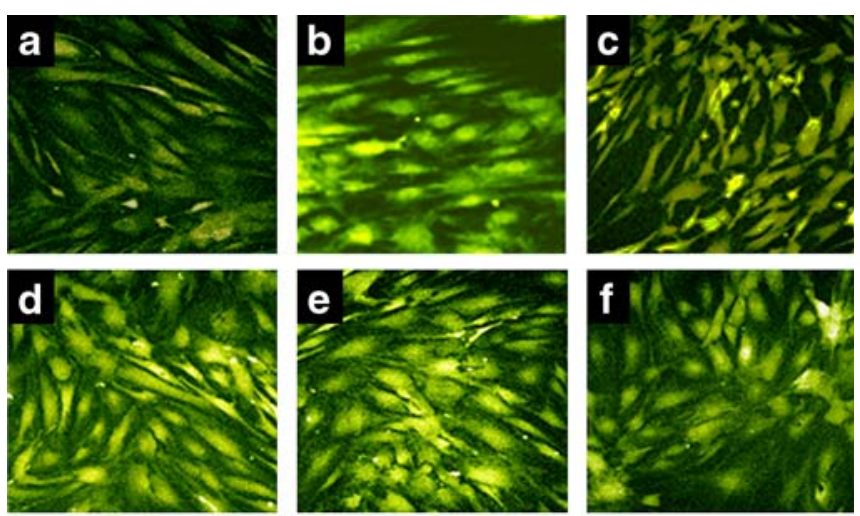

g

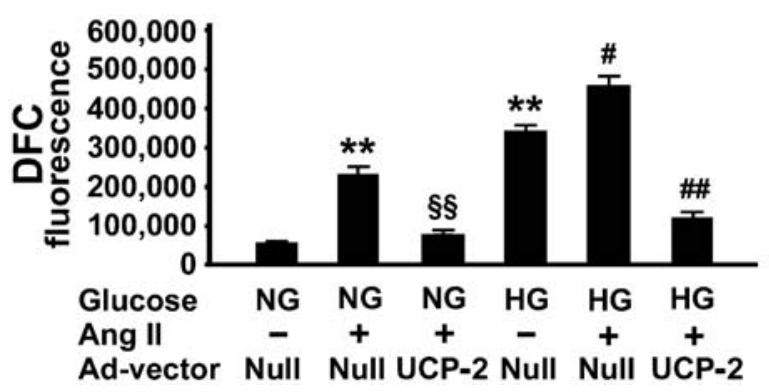

Fig. 2 Effect of Ad-UCP-2 on $\mathrm{H}_{2} \mathrm{O}_{2}$ production in response to high glucose and Ang II. Quiescent HVSMCs were infected with $6 \times 10^{6}$ of Ad-Null or Ad-UCP-2. Cells were maintained in media containing normal glucose or high glucose with $2 \%$ FBS for 2 days, after which they were processed for confocal microscopic examination using the oxidant-sensitive probes $2^{\prime}, 7^{\prime}$-dichlorofluorescein diacetate. Fully confluent fields of HVSMCs were randomly chosen and fluorescence was quantified using the NIH Image program. a $\mathrm{NG}^{+}$ Ad-Null; b NG+Ang II+Ad-Null; c NG+Ang II+Ad-UCP-2; d HG+ Ad-Null; e HG+Ang II+Ad-Null; f HG+Ang II+Ad-UCP-2. $N G$, normal glucose $(5 \mathrm{mmol} / \mathrm{l}) ; H G$, high glucose $(22 \mathrm{mmol} / \mathrm{l})$; Ang II, angiotensin II $(100 \mathrm{nmol} / \mathrm{l})$. Values are means \pm SEM of three independent experiments (g). ${ }^{* *} p<0.01$ vs NG; ${ }^{\S \S} p<0.01$ vs NG+Ang II; ${ }^{\#} p<0.05$ vs $\mathrm{HG} ;{ }^{\# \#} p<0.01$ vs $\mathrm{HG}+$ Ang II
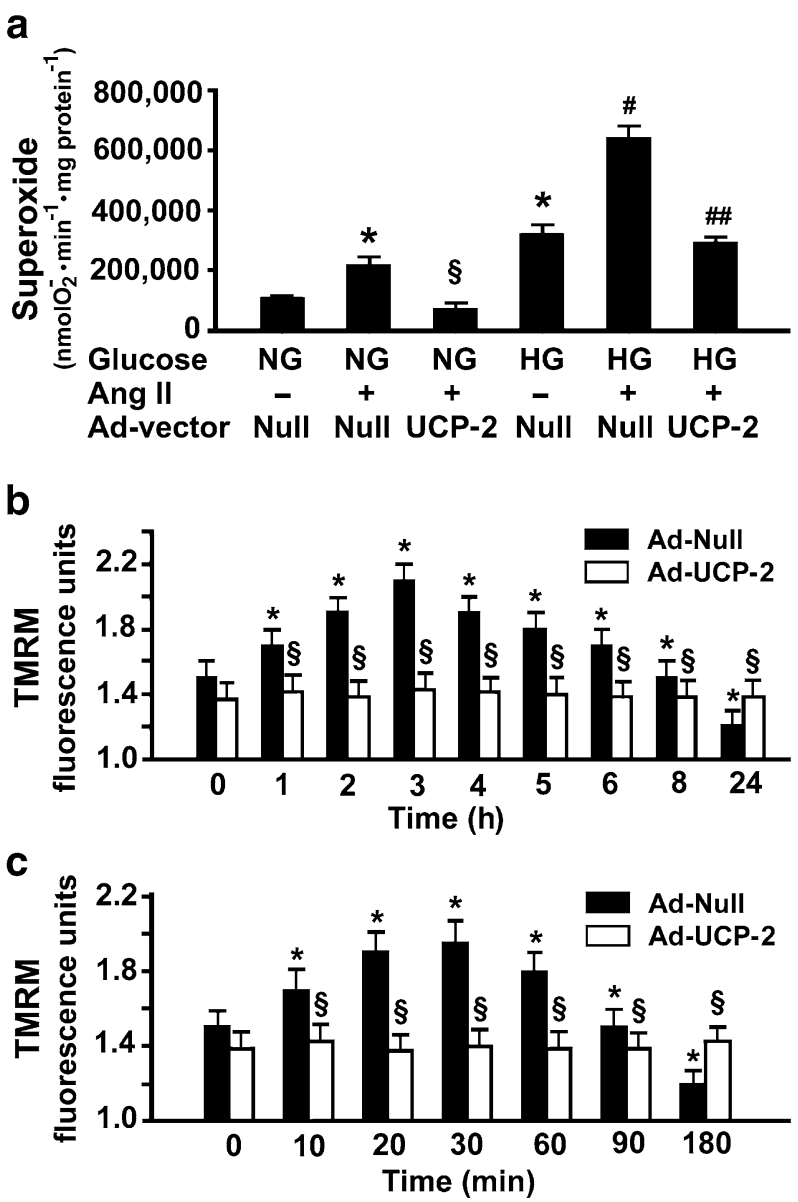

Fig. 3 Effects of Ad-UCP-2 on NAD(P)H oxidase activity (a) and mitochondrial membrane potential in response to high glucose (b) and Ang II (c). a HVSMCs were infected with $6 \times 10^{6}$ of Ad-Null or Ad-UCP-2 for $44 \mathrm{~h}$ under normal glucose or high glucose conditions, with or without Ang II for $4 \mathrm{~h}$. $N G$, normal glucose ( $5.5 \mathrm{mmol} / \mathrm{l}) ; H G$, high glucose (22 mmol/l); Ang II, angiotensin II (100 nmol/1); Null, Ad-Null; $U C P-2$, Ad-UCP-2. Values are means \pm SEM of three independent experiments. ${ }^{*} p<0.05$ vs $\mathrm{NG} ;{ }^{\S} p<0.05$ vs $\mathrm{NG}+$ Ang II; ${ }^{\#} p<0.05$ vs HG; ${ }^{\# \#} p<0.01$ vs HG+Ang II. b, c HVSMCs were infected with $6 \times 10^{6}$ of Ad-Null or Ad-UCP- 2 for $48 \mathrm{~h}$ and exposed to high glucose or Ang II. ${ }^{*} p<0.05$ vs basal; ${ }^{\S} p<0.05$ vs Ad-Null

3-h period respectively. There was a rapid increase in the membrane potential, which peaked at $3 \mathrm{~h}$ following exposure to glucose (Fig. 3b). The membrane potential in response to Ang II also increased and peaked at $30 \mathrm{~min}$ (Fig. 3c). The membrane potentials then decreased and were lower than those of the control cells. Overexpression of UCP-2 completely prevented glucose- and Ang-II-induced changes in the membrane potential observed in AdNull-infected cells (Fig. 3b, c).

Effect of Ad-UCP-2 on AP-1 activity Intracellular oxidative stress activates the redox-sensitive transcription factor AP-1 to influence various cellular functions. Increased AP-1 DNA binding activity in response to high glucose, in the presence or absence of Ang II, was significantly decreased by AdUCP-2, whereas Ad-Null had no effect (Fig. 4, $p<0.01$ ). 


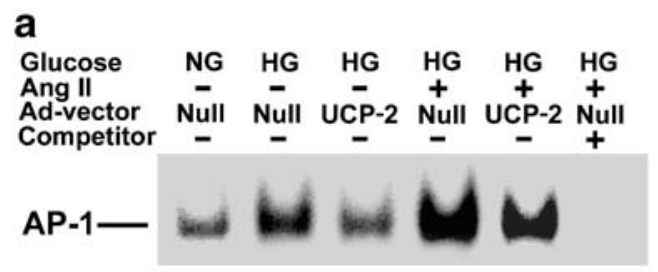

b

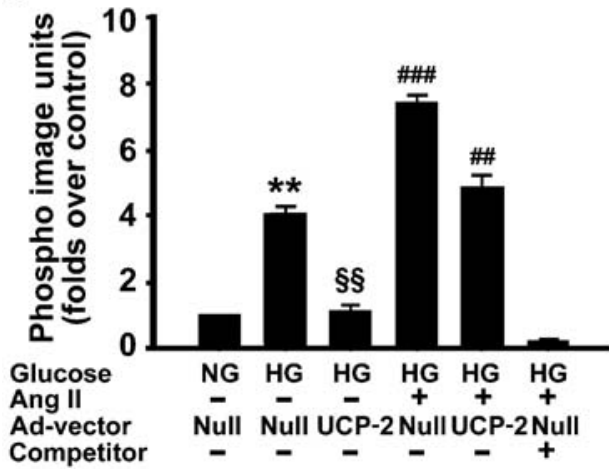

Fig. 4 Effect of Ad-UCP-2 on AP-1 DNA binding activity. $6 \mu \mathrm{g}$ of nuclear extract were incubated with radiolabelled AP-1 probe. a A typical example of a gel shift assay is shown for HVSMCs transfected with Ad-UCP-2. b Bars represent fold increase compared with normal glucose. $N G$, normal glucose $(5.5 \mathrm{mmol} / \mathrm{l}) ; H G$, high glucose (22 mmol/l); Ang II, angiotensin II (100 nmol/1); Null, AdNull; $U C P-2$, Ad-UCP-2 for adenoviral vector treatment. Values are means \pm SEM of three independent experiments. ${ }^{*} p<0.01$ vs NG; ${ }^{\S} p<0.01$ vs $\mathrm{HG} ;{ }^{\# \#} p<0.001$ vs NG; ${ }^{\# \#} p<0.01$ vs $\mathrm{HG}+$ Ang II

Effect of Ad-UCP-2 on PAI-1 mRNA expression Ang II and high glucose significantly increased PAI-1 mRNA expression (Fig. 5a, $p<0.01$ for each). Increased PAI-1 mRNA expression by Ang II or high glucose was reduced to the level observed under normal glucose conditions by the transfer of Ad-UCP-2, whereas Ad-Null did not affect PAI1 mRNA expression. The reduction of PAI-1 mRNA expression was dose dependent (Fig. 5b). a

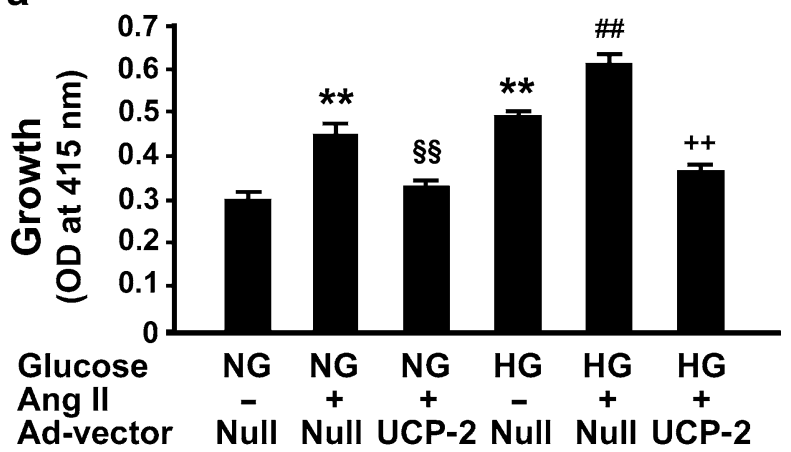

b

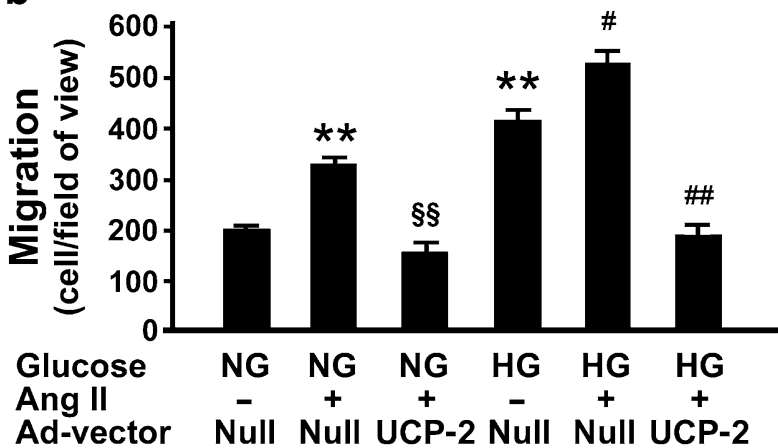

Fig. 6 Effect of Ad-UCP-2 on cell proliferation (a) and migration (b) in HVSMCs. $N G$, normal glucose $(5 \mathrm{mmol} / 1) ; H G$, high glucose ( $22 \mathrm{mmol} / \mathrm{l})$; Ang II, angiotensin II $(100 \mathrm{nmol} / \mathrm{l})$. Values are means \pm SEM of three independent experiments. a Cells were infected with $6 \times 10^{6}$ of Ad-Null or Ad-UCP-2. Three days after infection, growth was measured using a WST kit. Optical density (OD) values indicate growth activity of cells. ${ }^{*} p<<0.01$ vs $\mathrm{NG} ;{ }^{\S \S} p<0.01$ vs NG+Ang II; ${ }^{\text {\# }} p<0.01$ vs HG; ${ }^{++} p<0.01$ vs HG+Ang II. b Cells were infected with $6 \times 10^{6}$ of Ad-Null or Ad-UCP-2. Two days after infection, migration was measured by direct cell counting. ${ }^{* *} p<0.01$ vs NG; ${ }^{\S} p<0.01$ vs NG+Ang II; ${ }^{\#} p<0.05$ vs HG; ${ }^{\# \#} p<0.01$ vs $\mathrm{HG}+$ Ang II a

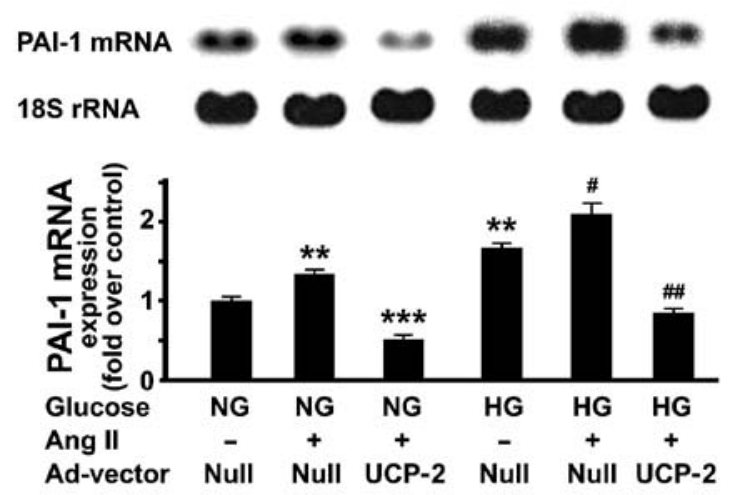

Fig. 5 Effect of Ad-UCP-2 on PAI-1 expression. $N G$, normal glucose $(5.5 \mathrm{mmol} / \mathrm{l}) ; H G$, high glucose $(22 \mathrm{mmol} / \mathrm{l}) ;$ Ang $I I$, angiotensin II $(100 \mathrm{nmol} / \mathrm{l})$. Values are means \pm SEM of three independent experiments. a HVSMCs were infected with either $6 \times 10^{6}$ of Ad-Null or Ad-UCP-2. HVSMCs were stimulated with Ang II or high glucose, with or without Ang II. Total RNA was extracted from HVSMCs. $10 \mu \mathrm{g}$ of total RNA were hybridised with PAI-1 probe. RNA quantity b

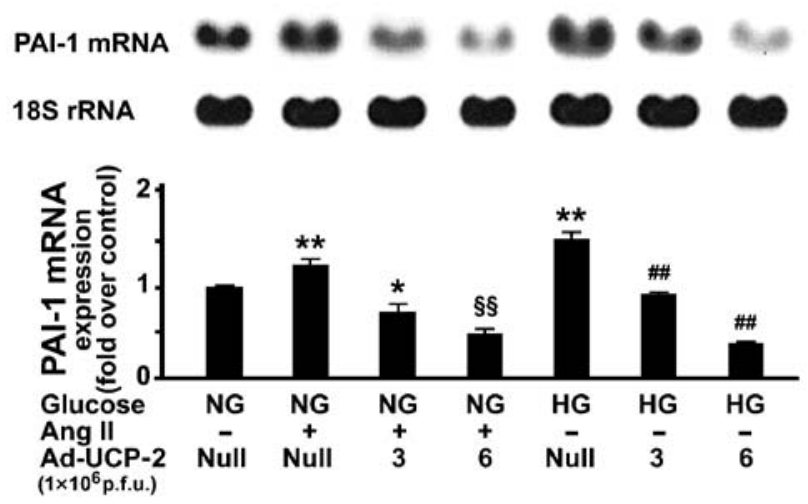

was normalised by $18 \mathrm{~S}$ rRNA. ${ }^{* *} p<0.01 \mathrm{vs} \mathrm{NG} ;{ }^{* * *} p<0.001 \mathrm{vs} \mathrm{NG}+$ Ang II; ${ }^{\#} p<0.05$ vs HG; ${ }^{\# \#} p<0.01$ vs HG+Ang II. b Dose-dependent effect of Ad-UCP-2 on PAI-1 expression. HVSMCs were infected with indicated dose of Ad-UCP-2. ${ }^{* *} p<0.01$ vs NG; ${ }^{*} p<0.05$ vs NG+ Ang II; ${ }^{\S} p<0.01$ vs NG+Ang II; ${ }^{\#} p<0.01$ vs HG. p.f.u., plaqueforming units 
Effect of Ad-UCP-2 on proliferation and migration of HVSMCs Ang II and high glucose stimulated the proliferation of primary cultured HVSMCs $(p<0.01$ for each). Transfection of Ad-UCP-2 significantly inhibited Ang-IIor high-glucose-mediated cell proliferation (Fig. 6a, $p<0.01$ for each).

Similarly, Ang II and high glucose stimulated the migration of cultured primary HVSMCs compared with that observed under normal glucose conditions $(p<0.01$ for each). This increase in HVSMC migration in response to Ang II or high glucose was markedly decreased by AdUCP-2 but not affected by Ad-Null (Fig. 6b, $p<0.01$ for each).

\section{Discussion}

We demonstrate here that UCP-2 is expressed in HVSMCs and is up-regulated by Ang II and/or high glucose. Adenoviral transfer of the $U C P-2$ gene to HVSMCs profoundly reduced ROS generation, AP-1 activity and mRNA expression of PAI-1, and also inhibited proliferation and migration of HVSMCs in response to high glucose and Ang II.

Hyperglycaemia and high-plasma Ang II concentrations are thought to play major roles in the pathogenesis of atherosclerosis in patients with diabetes and hypertension. Accumulating evidence indicates that high glucose and Ang II increase intracellular ROS production [12, 16, 17]. Consistent with these previous results, we found that high glucose and Ang II increase ROS generation, as well as the activity of the redox-sensitive transcription factor AP-1, and PAI-1 expression in HVSMCs. We also found that high glucose and Ang II increase proliferation and migration of HVSMCs. We previously demonstrated that inhibition of AP-1 by a sequence-specific decoy ODN inhibited highglucose- and Ang-II-induced cell proliferation and PAI-1 gene expression in primary cultured HVSMCs [13, 14]. When these results are combined with our current observations, it appears that high glucose and Ang II stimulate ROS generation in HVSMCs and that subsequent activation of AP-1 is responsible for increased PAI-1 expression as well as cellular proliferation and migration.

In this study, overexpression of the $U C P-2$ gene inhibited high-glucose- and Ang-II-stimulated AP-1 activity, PAI-1 expression, and proliferation and migration of HVSMCs. These results suggest that the effects of UCP-2 on HVSMC function are via the inhibition of AP-1 activity. However, direct inhibition of AP-1 by UCP-2 is less likely. The human UCP-2 promoter region has AP-1 binding sites near the transcription initiation site [28], which strongly suggests that transcription of UCP-2 is induced through activation of AP-1. High glucose and Ang II may increase UCP-2 expression by intracellular ROS-induced activation of AP-1 . Increases in UCP-2 may in turn decrease intracellular ROS and AP-1 activity and may limit cellular proliferation and PAI-1 gene expression of HVSMCs. In this regard, highglucose- or Ang-II-induced UCP-2 overexpression may be a compensatory mechanism for reducing intracellular ROS and limiting detrimental cellular effects of AP-1.
In cultured neuronal cells, high glucose induces initial hyperpolarisation followed by depolarisation of the inner mitochondrial membrane potential, which is associated with increased generation of ROS [27, 29]. Consistent with these studies, we found that high glucose and Ang II caused mitochondrial membrane hyperpolarisation followed by depolarisation. As expected, UCP-2 overexpression prevented these processes as well as ROS production [27]. Cell membrane $\mathrm{NAD}(\mathrm{P}) \mathrm{H}$ oxidase is another major source of ROS generation in VSMCs. Consistent with previous observations [12, 15, 26], both high glucose and Ang II increased NAD(P)H oxidase activity. Quite unexpectedly, we also found that UCP-2 overexpression significantly decreased high-glucose- and Ang-II-induced increases in $\mathrm{NAD}(\mathrm{P}) \mathrm{H}$ oxidase activity. The mechanism by which UCP2 overexpression decreases $\mathrm{NAD}(\mathrm{P}) \mathrm{H}$ oxidase activity is presently unknown, but may be due to its effect on the cellular NADH $/ \mathrm{NAD}^{+}$redox state. Bassenger et al. reported that reduction of the NADH concentration : $\mathrm{NAD}^{+}$concentration ratio (NADH : $\mathrm{NAD}^{+}$redox) by pyruvate infusion dose-dependently inhibited NAD(P)H oxidase activity and ROS generation in perfused guinea pig hearts [30]. Therefore, it can be assumed that high-glucose- and Ang-II-induced mitochondrial membrane hyperpolarisation, which reflects impairment of mitochondrial electron transfer and respiration, would increase $\mathrm{NAD}(\mathrm{P}) \mathrm{H}$ oxidase activity by increasing the cytosolic NADH : $\mathrm{NAD}^{+}$ratio. Conversely, normalisation of mitochondrial membrane potential by UCP-2 overexpression would decrease NAD(P)H oxidase activity by reducing the cytosolic $\mathrm{NADH}: \mathrm{NAD}^{+}$ratio. The mechanism by which Ang II induces mitochondrial membrane hyperpolarisation is yet to be investigated.

In summary, the present study shows that Ang-II- and high-glucose-induced ROS production up-regulates UCP-2 expression in HVSMCs. Adenovirus-mediated transfer of the $U C P-2$ gene diminished the expression of PAI-1 mRNA as well as cell proliferation and migration under high glucose and Ang II conditions. This study presents the possibility that the agents increasing UCP-2 expression in the vasculature may help prevent the development and progression of atherosclerosis in patients with diabetes and hypertension.

Acknowledgements This study was supported by a National Research Laboratory grant from the Korean Ministry of Science and Technology (M1040000000804J000000810).

\section{References}

1. Sowers JR, Epstein M, Frohlich ED (2001) Diabetes, hypertension, and cardiovascular disease: an update. Hypertension 37:1053-1059

2. Jones DW, Chambless LE, Folsom AR et al (2002) Risk factors for coronary heart disease in African Americans: the atherosclerosis risk in communities study, 1987-1997. Arch Intern Med 162:2565-2571

3. Ross R (1995) Cell biology of atherosclerosis. Annu Rev Physiol 57:791-804 
4. Newby AC, Zaltsman AB (1999) Fibrous cap formation or destruction - the critical importance of vascular smooth muscle cell proliferation, migration and matrix formation. Cardiovasc Res 41:345-360

5. Dzau VJ, Braun-Dullaeus RC, Sedding DG (2002) Vascular proliferation and atherosclerosis: new perspectives and therapeutic strategies. Nat Med 8:1249-1256

6. Schneiderman J, Sawdey MS, Keeton MR et al (1992) Increased type 1 plasminogen activator inhibitor gene expression in atherosclerotic human arteries. Proc Natl Acad Sci U S A 89:6998-7002

7. Ploplis VA, Cornelissen I, Sandoval-Cooper MJ, Weeks L, Noria FA, Castellino FJ (2001) Remodeling of the vessel wall after copper-induced injury is highly attenuated in mice with a total deficiency of plasminogen activator inhibitor-1. Am J Pathol 158:107-117

8. Peng L, Bhatia N, Parker AC, Zhu Y, Fay WP (2002) Endogenous vitronectin and plasminogen activator inhibitor-1 promote neointima formation in murine carotid arteries. Arterioscler Thromb Vasc Biol 22:934-939

9. Parker RA, Sabrah T, Cap M, Gill BT (1995) Relation of vascular oxidative stress, alpha-tocopherol, and hypercholesterolemia to early atherosclerosis in hamsters. Arterioscler Thromb Vasc Biol 15:349-358

10. Kunsch C, Medford RM (1999) Oxidative stress as a regulator of gene expression in the vasculature. Circ Res 85:753-766

11. Baynes JW (1991) Role of oxidative stress in development of complications in diabetes. Diabetes 40:405-412

12. Griendling KK, Minieri CA, Ollerenshaw JD, Alexander RW (1994) Angiotensin II stimulates NADH and NADPH oxidase activity in cultured vascular smooth muscle cells. Circ Res 74: $1141-1148$

13. Ahn JD, Morishita R, Kaneda Y et al (2002) Inhibitory effects of novel AP-1 decoy oligodeoxynucleotides on vascular smooth muscle cell proliferation in vitro and neointimal formation in vivo. Circ Res 90:1325-1332

14. Ahn JD, Morishita R, Kaneda Y et al (2001) Transcription factor decoy for activator protein-1 (AP-1) inhibits high glucose- and angiotensin II-induced type 1 plasminogen activator inhibitor (PAI-1) gene expression in cultured human vascular smooth muscle cells. Diabetologia 44:713-720

15. Chen XL, Tummala PE, Olbrych MT, Alexander RW, Medford RM (1998) Angiotensin II induces monocyte chemoattractant protein-1 gene expression in rat vascular smooth muscle cells. Circ Res 83:952-959

16. Du XL, Edelstein D, Rossetti L et al (2000) Hyperglycemiainduced mitochondrial superoxide overproduction activates the hexosamine pathway and induces plasminogen activator inhibitor-1 expression by increasing Sp1 glycosylation. Proc Natl Acad Sci U S A 97:12222-12226
17. Nishikawa T, Edelstein D, Du XL et al (2000) Normalizing mitochondrial superoxide production blocks three pathways of hyperglycaemic damage. Nature 404:787-790

18. Boss O, Hagen T, Lowell BB (2000) Uncoupling proteins 2 and 3: potential regulators of mitochondrial energy metabolism. Diabetes 49:143-156

19. Arsenijevic D, Onuma H, Pecqueur C et al (2000) Disruption of the uncoupling protein-2 gene in mice reveals a role in immunity and reactive oxygen species production. Nat Genet $26: 435-439$

20. Duval C, Negre-Salvayre A, Dogilo A, Salvayre R, Penicaud L, Casteilla L (2002) Increased reactive oxygen species production with antisense oligonucleotides directed against uncoupling protein 2 in murine endothelial cells. Biochem Cell Biol 80:757-764

21. Li LX, Skorpen F, Egeberg K, Jorgensen IH, Grill V (2001) Uncoupling protein 2 participates in cellular defence against oxidative stress in clonal $\beta$-cells. Biochem Biophys Res Commun 282:273-277

22. Blanc J, Alves-Guerra MC, Esposito B et al (2003) Protective role of uncoupling protein 2 in atherosclerosis. Circulation 107: 388-390

23. Choi YK, Kim YJ, Park HS et al (2003) Suppression of glomerulosclerosis by adenovirus-mediated IL-10 expression in the kidney. Gene Ther 10:559-568

24. Graham FL, van der Eb AJ (1973) A new technique for the assay of infectivity of adenovirus 5 DNA. Virology 52:456-467

25. McGrory MJ, Bautista DS, Graham FL (1988) A simple technique for the rescue of early region I mutations into infectious human adenovirus type 5. Virology 163:614-617

26. Lee HS, Son SM, Kim YK, Hong KW, Kim CD (2003) NAD (P)H oxidase participates in the signaling events in high glucose-induced proliferation of vascular smooth muscle cells. Life Sci 72:2719-2730

27. Vincent AM, Olzmann JA, Brownlee M, Sivitz WI, Russell JW (2004) Uncoupling proteins prevent glucose-induced neuronal oxidative stress and programmed cell death. Diabetes 53:726734

28. Tu N, Chen H, Winnikes U et al (1999) Molecular cloning and functional characterization of the promoter region of the human uncoupling protein-2 gene. Biochem Biophys Res Commun 265:326-334

29. Russell JW, Golovoy D, Vincent AM et al (2002) High glucoseinduced oxidative stress and mitochondrial dysfunction in neurons. FASEB J 16:1738-1748

30. Bassenge E, Sommer O, Schwemmer M, Bunger R (2000) Antioxidant pyruvate inhibits cardiac formation of reactive oxygen species through changes in redox state. Am J Physiol Heart Circ Physiol 279:H2431-H2438 